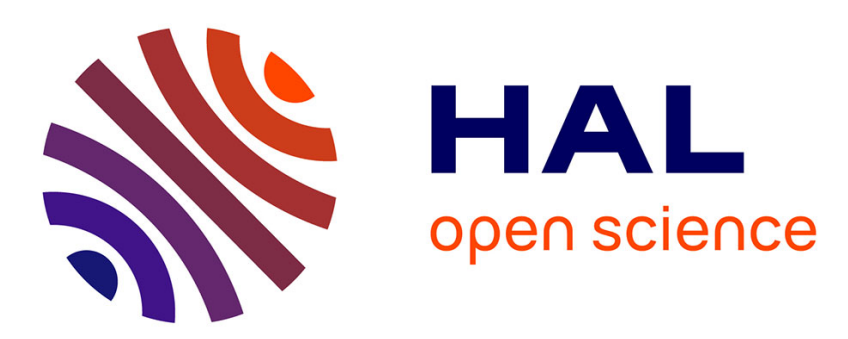

\title{
The challenge of access to refined fungal diagnosis: An investment case for low- and middle-income countries
}

\author{
Emma Orefuwa, Jean-Pierre Gangneux, David W Denning
}

\section{To cite this version:}

Emma Orefuwa, Jean-Pierre Gangneux, David W Denning. The challenge of access to refined fungal diagnosis: An investment case for low- and middle-income countries. Journal of Medical Mycology = Journal de Mycologie Médicale, 2021, 31 (2), pp.101140. 10.1016/j.mycmed.2021.101140 . hal03253459

\author{
HAL Id: hal-03253459 \\ https://hal.science/hal-03253459
}

Submitted on 11 Jun 2021

HAL is a multi-disciplinary open access archive for the deposit and dissemination of scientific research documents, whether they are published or not. The documents may come from teaching and research institutions in France or abroad, or from public or private research centers.
L'archive ouverte pluridisciplinaire HAL, est destinée au dépôt et à la diffusion de documents scientifiques de niveau recherche, publiés ou non, émanant des établissements d'enseignement et de recherche français ou étrangers, des laboratoires publics ou privés. 
Editorial

\section{The challenge of access to refined fungal diagnosis: a new step forward for low- and middle-income countries}

Emma Orefuwa ${ }^{1}$, Jean-Pierre Gangneux ${ }^{2,3^{*}}$, David W. Denning ${ }^{1,4}$

1. Global Action Fund for Fungal Infections (GAFFI), Geneva, Switzerland

2. Univ Rennes, $\mathrm{CHU}$, Inserm, Irset (Institut de recherche en santé, environnement et travail) UMR_S 1085, F-35000 Rennes, France

3. Société Française de Mycologie Médicale (SFMM), Paris, France

4. Manchester Fungal Infection Group, The University of Manchester, Manchester, UK;

${ }^{*}$ Corresponding author: JP Gangneux

Université de Rennes 1, Service de Parasitologie-Mycologie,

2 rue du Pr Léon Bernard, 35000 Rennes, France

Jean-pierre.gangneux@univ-rennes1.fr

Fungal pathogens cause serious morbidity and mortality worldwide, resulting in the death of 1.5 to 2.0 million people annually. $(1,2)$. The impact of fungal diseases is especially profound in low and middle income countries (LMIC's), where the combined effect of large vulnerable populations and favourable environmental conditions for fungal agents contribute to high disease burden. Despite their significant contribution to the global death toll, fungal diseases continue to be neglected in mainstream health programming. Large research gaps exist, masking the true magnitude of fungal disease burden and its socio-economic impact and as a consequence, its prioritisation within the global health agenda.

Data from modelling suggests that of the $~ 530,000$ AIDS deaths in Africa, over 250,000 are probably attributable to fungal diseases (3). High quality cancer and intensive care needs supportive diagnosis to prevent death from fungal infections. Tuberculosis(TB)-like fungal infections of the chest, notably chronic pulmonary aspergillosis and histoplasmosis, need addressing in TB programs in Africa. There is a huge problem of skin, hair and nails infection in African children, 135 million with tinea capitis as a quantified example (3). Fungal asthma in Africa can be addressed with antifungal therapy $(4,5)$. In LMIC's, the aforementioned risk factors are underpinned by weak health systems, insufficiently 
trained healthcare personnel, limited availability of diagnostic tools and poor access to new-line antifungal therapies (6).

In robust health systems, the majority of clinical decision making is informed by diagnostic test results which allow for treatment options to be based on pathophysiological evidence. Fungal diseases are complex and numerous, often requiring specialist skills, facilities and infrastructure for their accurate diagnosis and clinical management. In LMIC settings, where awareness of fungal diseases is generally low compared to other infectious diseases, misdiagnosis is common. Scant resources and the threat of catastrophic out of pocket payments for patients often drives empirical medical practice.

In recent decades, the advent of highly sensitive, highly specific rapid diagnostics assays presents a transformational opportunity for countries with systemic healthcare delivery challenges. The availability of low cost, quick turnaround diagnostics, maximises patient survival chances when fungal diseases are otherwise omitted from differential diagnoses considerations.

The availability of these tests would allow LMIC's to 'leapfrog' sole reliance on traditional diagnostic methods such as culture and direct microscopy, and would facilitate universal health coverage by allowing marginalised communities to access quality diagnostics at lower tier health facilities.

A number of guidance documents to aid countries with the roll out of essential diagnostics exist. The Global Action Fund for Fungal Infections (GAFFI) has produced a consensus roadmap for the reduction of fungal diseases, which contains core requirements for effective administration of diagnostics (7).

The WHO model list of essential diagnostics (EDL) is a universally accepted guide that is an indispensable resource for the development of national essential diagnostics lists in countries, enabling them to prioritise investments for at risk populations. GAFFI, in collaboration with a number of leading medical mycology societies worldwide, has long been advocating for the adoption of new generation diagnostics onto the EDL, with some success (8). Due to these efforts, several important diagnostic tools are now included on the WHO EDL. Recently, Aspergillus antigen, Aspergillus IgG antibody and Pneumocystis jirovecii nucleic rapid tests have been incorporated into the latest version of the WHO EDL, released in January 2021 (Table 1) (9).

This revised list of Essential Diagnostic tests is a positive step towards universal access to diagnostics for better management of severe fungal diseases and should serve as a standard for fungal diseases diagnostics in all countries. Currently, little data exists on the availability of fungal disease diagnostics in LMIC's, leading to piecemeal roll out of diagnostic tools, which are often confined to small scale research studies, or short term programs in limited sites. In order to adequately serve population needs, a public health approach is required, whereby fungal disease diagnostic tools are integrated into clinical care pathways via sustainable models.

As part of these collective efforts to address fungal disease diagnostic gaps in LMIC's, GAFFI has initiated the first multi-country assessment of access to fungal disease diagnostics in Africa, with the primary objective of collecting data to evaluate the capacity of health systems to diagnose fungal disease.

A semi-structured questionnaire was developed and then disseminated to leading laboratory and clinical experts in countries to complete. The inclusion criterion for the assessment is all countries in Africa with a population $>1$ million. The first part of the assessment interrogates the availability and accessibility of key diagnostics for fungal disease at all levels of the health system, spanning primary to tertiary care. The list of diagnostics included in the survey is based on the repertoire of diagnostics 
contained in the WHO EDL. The second part of the assessment captures CD4 testing modalities such as criteria for performing CD4 counts and equipment used. The final section of the questionnaire collects information about essential clinical procedures required to support fungal disease diagnosis, such as imaging of the chest and brain and specialized means of taking samples, e.g. skin biopsy, bronchoscopy, corneal scraping and lumbar puncture. We have also included spirometry to diagnose asthma and chronic obstructive pulmonary disease.

Once collected, data is confirmed with country experts via teleconference. During this process, qualitative information is documented to provide context to the quantitative responses provided.

Results are then validated with local health authorities. The final outputs for the diagnostics assessment will be a country profile narrative summarising results and a set of digital maps illustrating level of access and penetration in comparison with other countries.

Country specific and regional recommendations will be shared with national and regional authorities, non governemental organisations, HIV, AIDS and TB programmes and other relevant stakeholders in order to strengthen laboratory and clinical capacity for fungal disease diagnosis (10). A report summarising findings from the Africa region will be published in late 2021. GAFFI will work with medical mycology associations such as ECMM, ISHAM, SFMM and other related special interest groups from the global north and south to advocate for the implementation of recommended tests on the EDL in LMIC's. Building a critical mass of expertise in countries to support uptake of diagnostic tools is essential.

It is anticipated that this important landscaping exercise will serve as the catalyst for a paradigm shift with regards to prioritisation of diagnostics for fungal disease in Africa by health authorities and global health actors.

Table 1. WHO Essential diagnostics tests and drugs for the management of severe fungal diseases.

\begin{tabular}{|l|l|}
\hline \multicolumn{1}{|c|}{ WHO Essential diagnostics tests } & \multicolumn{1}{|c|}{ WHO Essential antifungal drugs } \\
\hline Histopathology & Amphotericin B (deoxycholate or \\
Clinical microbiology (direct microscopy, fungal culture, blood & liposomal) \\
culture) & Fluconazole \\
Cryptococcal antigen & Flucytosine \\
Histoplasma antigen & Griseofulvin \\
Pneumocystis jirovecii nucleic acid test* & Itraconazole \\
Aspergillus antigen test* & Nystatin eye drops \\
Aspergillus IgG antibody* & Voriconazole \\
\hline
\end{tabular}

*incorporated in the last version issued January $29^{\text {th }} 2021$

(https://www.who.int/medical devices/diagnostics/selection in-vitro/en/)

\section{References}

1. Brown GD, Denning DW, Gow NAR, Levitz $S$, Netea M, White T. Human fungal infections: the hidden killers. Sci Transl Med. 2012:4:165rv13.

2. Denning DW. The ambitious ' $95-95$ by 2025 ' roadmap for the diagnosis and management of fungal diseases. Thorax 2015; 70:613-4.

3. Bongomin F, Olum R, Nsenga L, Namusobya M, Russell L, de Sousa E, Osaigbovo II, Kwizera R, Baluku JB. Estimation of the burden of tinea capitis among children in Africa. Mycoses

2021;64(4):349-363. 
4. Kwizera R, Musaazi J, Meya DB, Worodria W, Bwanga F, Kajumbula H, Fowler SJ, Kirenga BJ, Gore $R$, Denning DW. Burden of fungal asthma in Africa: A systematic review and meta-analysis. PLoS One 2019;14:e0216568.

5. Rapeport WG, Ito K, Denning DW. The role of antifungals in the management of patients with severe asthma. Clin Transl Allergy 2020;10:46.

6. Global Action Fund for Fungal Infections. "Developing a coalition roadmap for integration of fungal disease pathways and AMR solutions into health systems in Latin America". Meeting Lima, Peru September 2019; Report July 2020 https://www.gaffi.org/global-fungal-infection-forum-4-in-lima/

7. Global Action Fund for Fungal Infections. "95-95 by 2025. Improving outcomes for patients with fungal infections across the world; A roadmap for the next decade." Meeting Seattle, USA, February 2015; Report May 2015 http://www.gaffi.org/roadmap/

8. Bongomin F, Govender NP, Chakrabarti A, Robert-Gangneux F, Boulware DR, Zafar A, Oladele RO, Richardson MD, Gangneux JP, Alastruey-Izquierdo A, Bazira J, Boyles TH, Sarcarlal J, Nacher M, Obayashi T, Worodria W, Pasqualotto AC, Meya DB, Cheng B, Sriruttan C, Muzoora C, Kambugu A, Rodriguez Tudela JL, Jordan A, Chiller TM, Denning DW. Essential in vitro diagnostics for advanced HIV and serious fungal diseases: international experts' consensus recommendations. Eur J Clin Microbiol Infect Dis. 2019 Sep;38(9):1581-1584. doi: 10.1007/s10096-019-03600-4. PMID: 31175479.

9. 3rd Essential Diagnostics' List Launch https://www.gaffi.org/3rd-essential-diagnostics-list-launch/

10. Oladele RO, Akase IE, Fahal AH, Govender NP, Hoenig/ M, Gangneux JP, Chiller TM, Denning DW, Cornely OA, Chakrabarti A. Bridging the knowledge gap on mycoses in Africa: Setting up a Pan-African Mycology Working Group. Mycoses. 2020 Mar;63(3):244-249. doi: 10.1111/myc.13044. Epub 2019 Dec 30. PMID: 31829454. 